\title{
Utilização da entropia informacional na seleção de indicadores financeiros mais relevantes para tomada de decisão no setor público:o caso dos estados brasileiros
}

Paulo Sérgio Almeida-Santos

Mestre em Ciências Contábeis pela Universidade Regional de Blumenau (FURB). Professor da Faculdade de Administração e Ciências Contábeis (FACC) da Universidade Federal de Mato Grosso (UFMT)

Irani Rocha

Mestre em Ciências Contábeis pela Universidade Regional de Blumenau (FURB).Professora do Centro Universitário e Faculdade Metropolitana de Blumenau

Nelson Hein

Doutor em Engenharia de Produção pela Universidade Federal de Santa Catarina (UFSC).Pós-Doutor pela Associação Instituto Nacional de Matemática Pura e Aplicada (IMPA) e pela Anderson School of Management da Universidade do Novo México (EUA).Professor permanente no Programa de Pós-Graduação em Ciências Contábeis (PPGCC) da Universidade Regional de Blumenau

http://dx.doi.org/10.1590/1981-5344/1780

O propósito do artigo consiste em verificar, dentre uma seleção não aleatória de indicadores financeiros aplicados às demonstrações contábeis do setor público, quais deles possuem o maior peso ou nível de informação, medidos por meio da entropia informacional. Trata-se uma pesquisa quantitativa do tipo documental e descritiva, em que é pesquisado o caso dos estados brasileiros. Firmado na teoria da informação, na qual a entropia é propagada, são selecionados intencionalmente oito indicadores financeiros de análise de balanços aplicados exclusivamente a entidades governamentais. Ao proceder com cálculo da entropia informacional sobre os indicadores selecionados - aqueles de caráter orçamentário apresentaram um grau de entropia máxima; 
os de caráter patrimonial - apresentaram grau de entropia mínima; isto permite uma breve conclusão, em que indicadores orçamentários, por ser regrados pelos limites da $L R F$, são considerados dentro da ótica da entropia informacional como indicadores irrelevantes, ao passo que os indicadores patrimoniais são tidos por ela como relevantes, por apresentarem maior peso/grau de informação.

Palavras-chave: Teoria da informação; Entropia informacional; Análise de balanços; Tomada de decisão; Setor público.

\section{Use of informational entropy in the selection of indicators financial highlights for decision making in public sector: the case of Brazilian states}

The purpose of the paper is to verify from a non-random selection of indicators applied to financial statements for the public sector, which ones have the highest weight or level of information measured by the informational entropy. This is a quantitative and descriptive type documentary, it is researched the case of Brazilian states. Signed in information theory, where entropy is propagated, are intentionally selected eight indicators of financial balance sheet analysis applied only to government entities. When proceeding with the informational entropy calculation on the selected indicators - those character budget showed a degree of maximum entropy, the character sheet - showed minimal degree of entropy, this allows a brief conclusion, that indicators be regulation budget by the limits of LRF are considered within the perspective of informational entropy as indicators irrelevant, while the asset indicators are regarded as relevant by it, because they have greater weight/grade information.

Keywords: Information theory; Informational entropy; Balance sheet analysis; Decision making; Public sector.

Recebido em 09.04.2013 Aceito em 07.02.2014 


\section{Introdução}

Devido à impulsão da globalização em âmbito mundial, tanto as entidades privadas quanto governamentais têm a necessidade de se adequarem ao novo mercado, produzindo, sobretudo, informações fidedignas para a tomada de decisão dos seus diversos stakeholders.

No instante em que as entidades vêm adquirindo maior consciência da importância da informação, essas têm buscado produzir e oferecer informações mais adequadas em relação às necessidades dos usuários (SOUZA; DIAS; NASSIF, 2011). Neste contexto, a ciência da informação passa ser um tema emergente em diversas áreas, especialmente por sua relevância social (ver FREIRE et al., 2010; SOUZA; DIAS; NASSIF, 2011).

Em meio a esse ambiente púbere, verificam-se as múltiplas diferenças entre entidades, ramos, setores, etc. Neste aspecto, existe uma atenção especial voltada ao setor público (MATIAS; CAMPELLO, 2000).

Dentre as discrepâncias vivenciadas entre os setores privado e público, por exemplo, está a análise de balanços, que, de acordo com Andrade (2002), é uma ferramenta gerencial que poderia ser melhor aproveitada, com o intuito de averiguar a situação financeira e patrimonial das entidades governamentais.

Para Lima Júnior (2007), as informações extraídas a partir da análise de balanços possibilitam constatar os pontos positivos e negativos sobre a aplicação dos recursos públicos, além de auxiliar em sua gestão. Utilizando as técnicas de análise de balanço, "o gestor pode verificar diversas situações de gestão, ou seja, qual a capacidade de geração de receita, qual a dependência financeira do município diante do Estado e também da União entre outros fatores inerentes a estas organizações" (LIMA JÚNIOR, 2007, p. 13).

Diante disso, a Secretaria do Tesouro Nacional (STN) (2011) afirma que a análise das demonstrações contábeis "tem por objetivo assegurar a consistência e a transparência das informações consolidadas e se fundamenta na avaliação da organização dos dados no formato em que serão divulgados". Neste contexto, uma análise eficiente, embasada em relatórios contábeis fidedignos, permite ao gestor público uma tomada de decisão em real cumprimento aos princípios administrativos, garantindo a economicidade, equilíbrio e eficiência na aplicação dos recursos públicos (ANDRADE, 2002).

Outros estudos já trataram da análise de indicadores no setor público, utilizando metodologias diferenciadas, na tentativa de observar quais desses são os de maior relevância em termos informacional (por exemplo, ver: FERNANDES, 1996; LIMA JÚNIOR, 2007; COELHO; QUINTANA, 2008; NOGUEIRA; RODRIGUES JÚNIOR, 2008; TREVISAN et al., 2009; BONIFACIO et al., 2009; SOARES et al., 2011).

De acordo com Lima Júnior (2007, p. 14), percebe-se que, no setor público, "existe um vasto campo para pesquisa, cujos resultados podem proporcionar aos gestores públicos subsídios administrativos, ampliando a 
gestão além dos objetivos legais". Nesta perspectiva, as dificuldades relacionadas à mensuração do desempenho das contas públicas possibilitam o interesse em se buscar novas técnicas que possam ser capazes de auxiliar o gestor público na tomada de decisão, bem como a sociedade - quando esta quiser avaliar a gestão de sua cidade.

Doravante, a técnica da entropia informacional pode ser uma ferramenta capaz de diagnosticar quais indicadores aplicados às demonstrações contábeis do setor público possuem o maior peso de informação, i.e., quais apresentam maior relevância.

Propagada na área da Física - mais precisamente nos estudos da termodinâmica - a entropia foi criada por Claude E. Shannon, em 1948, para mensurar o nível de informação baseado em probabilidades. Não obstante, a entropia não está associada somente à termodinâmica, contudo, pode ser utilizada em conjunturas ligadas à teoria da probabilidade (BENTES; MENEZES; MENDES, 2009). Por ser uma técnica capaz de mostrar informações mais precisas sobre um determinado objeto de pesquisa, Rifkin (1980) assegura que a entropia pode ser aplicada em diversas áreas, além das exatas, na qual foi criada. Neste contexto, Rifkin (1980) cita a ciência social. Na situação da teoria da informação, a entropia expressa o nível de desordem/imprevisibilidade da informação quanto mais informação no conjunto menor a entropia - quanto menos informação no conjunto maior a entropia.

Levando-se em consideração o que brevemente foi exposto, o propósito do artigo consiste em verificar, dentre uma seleção não aleatória de indicadores financeiros aplicados às demonstrações contábeis do setor público, quais deles possuem o maior peso ou nível de informação, medidos por meio da entropia informacional. Os indicadores selecionados com base na literatura específica de análise de balanço governamental são: (i) indicador resultado orçamentário total; (ii) indicador do resultado orçamentário corrente; (iii) indicador do resultado orçamentário de capital; (iv) indicador da situação financeira; ( $v$ ) indicador da situação permanente; ( $v i)$ indicador resultado patrimonial; (vii) utilização de capital de terceiros; e (viii) participação do passivo financeiro a descoberto nas receitas orçamentárias. O objetivo apresentado é na tentativa de responder ao seguinte questionamento: será que a entropia informacional é capaz de predizer, dentre um conjunto de indicadores financeiros aplicados exclusivamente às demonstrações contábeis de entidades governamentais, quais são os mais relevantes para tomada de decisão neste setor, i.e., aqueles que carregam maior peso informacional?

Teoricamente o estudo contribui para literatura sobre teoria da informação, sobretudo, no que tange à utilização da entropia como ferramenta de apoio à tomada de decisão. De modo prático, o estudo enseja à academia e aos gestores governamentais que a utilização da entropia informacional pode ser útil na seleção de informações, separando as mais relevantes das menos irrelevantes, neste caso, a seleção de indicadores financeiros. Socialmente, o estudo contribui, salientando que a 
utilização de técnicas defendidas dentro da teoria da informação, por exemplo, a entropia, pode ser utilizada como uma ferramenta de apoio à tomada de decisões pelos entes públicos, permitindo, quiçá, mais eficiência e economicidade na aplicação dos recursos públicos em benefício da sociedade, como, também, dando maior respaldo à instrumentalização do controle social.

\section{Teoria da informação e a entropia informacional}

A Teoria da Informação foi fundada, em 1948, por Claude E. Shannon e está relacionada tanto com as questões relativas à Teoria da Comunicação quanto às questões relativas a diversas áreas do conhecimento, como: "Criptogra_a e Criptoanálise, Teoria de Probabilidade, Inteligência Artificial, Economia, etc." (FERNANDES; AZEVEDO, 2006).

A ciência da informação pode ser apresentada como uma área do conhecimento recente que está em constante desenvolvimento, em especial na área das ciências socais. Nesse sentido, Amorin (2007, p. 17) comenta que "a consolidação da ciência da informação é um processo de construção relativamente recente em torno de seu objeto, o qual pode ser definido como: a promoção da comunicação da informação desejada entre seu produtor e o destinatário de forma eficaz".

Partindo-se do pressuposto que a informação contábil é essencial dentro do processo de comunicação e apropriação do conhecimento, Souza e Stumpf (2009) inferem que a ciência da informação é caracterizada como uma ciência interdisciplinar, que trata de questões voltadas para a geração, comunicação e apropriação do conhecimento. Nesse sentido, Borko (1968, p. 3 apud AMORIN 2007) define a ciência da informação como uma ciência interdisciplinar, que analisa os atributos, as técnicas e os procedimentos da informação; objetivando sua armazenagem, reocupação e disseminação, quer seja manualmente, quer seja mecanicamente.

Ao atrelarem-se as relações existentes entre a ciência da informação com outros campos do conhecimento, como a Contabilidade, as análises relativas ao controle da informação contábil e seu conteúdo partem da função social da Contabilidade, sendo que essa função é o fundamento da divulgação das informações aos usuários (AMORIN, 2007).

A ciência da informação é uma área voltada às questões científicas e práticas profissionais, que visa resolver problemas essenciais da comunicação do conhecimento entre as pessoas, em relação ao uso da informação e de sua necessidade, nos contextos: social, institucional, individual. Nesta perspectiva, "são consideradas de particular interesse as vantagens das modernas tecnologias informacionais" (SERACEVIC, 1996, p. 47 apud AMORIN, 2007, p. 18).

Araújo (2003) cita que a ciência da informação é definida como uma "ciência social aplicada". A inserção daquela, nesta, iniciou-se a partir da década de 70, em que discussões sobre a ciência social visavam à 
modificação e atuação da ciência da informação, enfatizando que é necessário estarem interligados: a informação e os processos sociais, para que haja a evolução das ciências sociais. Nesta perspectiva, Pinheiro e Loureiro (1995) comentam que a teoria da informação de Shannon (1948) traz importante contribuição ao conceito de informação; sendo esta considerada o resultado do processamento, manipulação e organização de dados de tal forma que represente um acréscimo ao conhecimento da pessoa que a recebe (STRASSBURG et al., 2007).

Rudolf Julius Emanuel Clausius lançou, em 1865, as duas primeiras Leis da Termodinâmica. A primeira lei afirmava que a energia total do universo é constante e a segunda lei afirmava que a entropia total do universo está aumentando em direção a um valor máximo (COVENEY; HIGHFIELD, 1990). Nesse sentido, Epstein (1986) comenta que, em meados de 1864, Clausius propôs a quantificação da entropia física, como uma transformação acompanhada de conversão entre as energias térmica e mecânica.

A lei da entropia consiste que toda a energia em um sistema isolado move-se do estado ordenado para o estado desordenado. Dessa forma, o estado mais ordenado, no qual a concentração é maior, é considerado o estado da entropia mínima. Em contrapartida, o estado mais desordenado é considerado o estado da entropia máxima (RIFKIN, 1980; COVOLAN, 2003). Dessa forma, a noção de entropia está ligada ao grau de desorganização existente na fonte (podendo ser chamado na estatística de dispersão, i.e. dados dispersos/espalhados).

O conceito de entropia pode ser considerado como uma das grandes realizações das ciências. A entropia constitui a essência da mecânica estatística e também exerce papel central na teoria da informação. A sua interpretação física beneficia outras áreas do conhecimento, tais como filosofia, economia e computação (BORGES, 1999).

A importante inovação de Shannon (1948) tem como objetivo, demonstrar que o conceito de entropia não se restringe apenas à termodinâmica, mas pode ser aplicado no contexto que envolva probabilidades (BENTES; MENEZES; MENDES 2009). Assim, o conceito da entropia ultrapassou em praticamente todas as áreas do conhecimento, tais como, biologia, economia, sociologia, psicologia e até mesmo a arte (RIFKIN, 1980; BORGES, 1999).

Shannon (1948) criou o conceito de entropia para medir a quantidade de informação com base na incerteza, ou seja, algo distinto do conceito em termodinâmica (STURZBECHER, 2006).

Com base no total da informação, é possível prever a quantidade de informações intrínsecas em uma medida inicial e, assim, a métrica da entropia permite calcular a velocidade a que esta informação diminui (BENTES; MENEZES; MENDES, 2009). Para Pineda (2010, p. 22), "a entropia é um estado dinâmico que varia em função do estado inicial de organização da matéria e do tempo, caracterizando um processo irreversível". Quanto maior a desorganização (entropia, incerteza), maior o potencial de informação dessa fonte (SHANNON, 1948). De acordo com 
Gonçalves (2008), a incerteza pode ser caracterizada pela quantidade de informação que a ocorrência de um evento fornece, sendo a incerteza traduzida com base na probabilidade de ocorrência de seu evento. Assim, não se tem nenhum acréscimo de informação em um evento cuja ocorrência é certa, ou seja, a certeza de ocorrência contém toda informação. Para o autor, "pode-se dizer que a determinação da quantidade de informação produzida pela ocorrência de um evento é determinada pela quantidade de surpresa que essa ocorrência traz" (GONÇALVES, 2008, p. 16).

Mattos e Veiga (2002) mencionam que na teoria da informação, a entropia, refere-se à incerteza probabilística relacionada a uma distribuição de probabilidade, ou seja, o grau de incerteza é reflexo de uma determinada distribuição e distintas distribuições estão associadas a distintos graus de improbabilidade. Dessa maneira, de acordo com o autor, "quanto mais espalhada à distribuição de probabilidade, maior incerteza ela irá refletir" (MATTOS; VEIGA 2002, p. 39).

Nesse contexto, Bentes, Menezes e Mendes (2009) destacam que evidências empíricas têm demonstrado que, muitas vezes, uma sequência de valores financeiros não apresenta um comportamento linear, relacionando-se a um movimento caótico. Dessa forma, os autores procuraram estudar o papel da entropia como meio de quantificar a previsibilidade e relatar a situação não linear nos mercados financeiros. Muitas vezes, os valores inicialmente se aproximam, mas, posteriormente, podem ficar distantes um do outro e, por fim, podem voltar a se aproximar, caracterizando, dessa forma, uma mistura. Quanto menos eventos prováveis, ou seja, os eventos apresentam-se mais distintos, o resultado da entropia é considerado mais surpreendente, o efeito surpresa é maior, enquanto mais eventos prováveis, no sentido de eventos menos distintos, o resultado da entropia é considerado menos surpreendente, o efeito surpresa é menor (BENTES; MENEZES; MENDES, 2009).

Zeleny (1982) trabalha cada item a ser utilizado para o cálculo da entropia como atributos. Nesse sentido, os atributos $\left(\lambda_{i}\right)$, deverão ser classificados por grau de importância pelo decisor, ou seja, de baixa para alta importância, em uma dada situação de decisão. O grau de importância, é diretamente relacionada à quantidade de informações intrínsecas geradas por um conjunto de possíveis alternativas de cada iésimo atributo (ZELENY, 1982). De acordo com Zeleny (1982), há duas componentes na formação do peso $\lambda_{\mathrm{i}}$ : (i) Conceito de relatividade estável a prior, $i$ atribuindo importância $\mathrm{w}_{\mathrm{i}}$, refletindo a cultura individual, cultural, genética, psicológica, social e ambiental (meio); e (ii) Relatividade instável, conceito contexto-dependente da importância informacional $\lambda_{i}$, baseado em um conjunto particular de possíveis alternativas de uma dada situação decisória. Esses pesos são sensíveis a qualquer mudança em ambos os conjuntos $\chi$ (valores da matriz de decisão) e $D$ (valores normalizados da matriz de decisão), e as flutuações nas quantidades de informação intrínseca gerada por ambos. O autor considera a entropia 
como uma medida simples, mas poderosa, por causa da quantidade de informações fornecida por uma fonte de informação dada (ZELENY, 1982).

O cálculo da entropia informacional é apresentado em Rocha (2010, pp. 61-63) da seguinte forma:

Sendo, $d_{i}=\left(d_{i}^{1}, d_{i}^{2}, \ldots, d_{i}^{m}\right)$ os valores normalizados, em que: $\mathrm{d}_{\mathrm{i}}^{\mathrm{k}}=\frac{\mathrm{x}_{\mathrm{i}}^{\mathrm{k}}}{\mathrm{x}_{\mathrm{i}}^{*}}$ caracteriza o conjunto $D$, em termos do i-ésimo atributo.

Encontra-se, portanto, $\mathrm{D}_{\mathrm{i}}=\sum_{\mathrm{k}=1}^{\mathrm{m}} \mathrm{d}_{\mathrm{i}}^{\mathrm{k}} ; \mathrm{i}=1,2, \ldots, \mathrm{n}$. Busca-se, após, a medida de entropia do contraste da intensidade para o i-ésimo atributo calculado por: $\mathrm{e}\left(\mathrm{d}_{\mathrm{i}}\right)=-\alpha \sum_{\mathrm{k}=1}^{\mathrm{m}} \frac{\mathrm{d}_{\mathrm{i}}^{\mathrm{k}}}{\mathrm{D}_{\mathrm{i}}} \operatorname{Ln}\left(\frac{\mathrm{d}_{\mathrm{i}}^{\mathrm{k}}}{\mathrm{D}_{\mathrm{i}}}\right)$ onde: $\alpha=\frac{1}{\mathrm{e}_{\max }}>0$ e $\mathrm{e}_{\max }=\operatorname{Ln}(\mathrm{m})$. Verificando, ainda, que $0 \leq \mathrm{d}_{\mathrm{i}}^{\mathrm{k}} \leq 1$ e $\mathrm{d}_{\mathrm{i}}^{\mathrm{k}} \geq 0$.

Sendo todos os $d_{i}^{k}$ iguais para um dado i, então, $\frac{d_{i}^{k}}{D_{i}}=\frac{1}{n}$ e e $\left(d_{i}\right)$ assumem valor máximo, isto é, $e_{\max }=\operatorname{Ln}(m)$. Ao se fixar $\alpha=\frac{1}{\mathrm{e}_{\max }}$, determinam-se $0 \leq \mathrm{e}\left(\mathrm{d}_{\mathrm{i}}\right) \leq 1$ para todos os $\mathrm{d}_{\mathrm{i}}{ }^{\prime} \mathrm{s}$. Tal normalização é necessária para efeitos comparativos.

Neste caso, a entropia total de $D$ é definida por: $E=\sum_{i=1}^{n} \mathrm{e}\left(\mathrm{d}_{\mathrm{i}}\right)$.

Para efeitos de análise, quanto maior for $e\left(d_{i}\right)$ menor será a informação transmitida pelo i-ésimo atributo. Caso $e\left(d_{i}\right)=e_{\max }=\operatorname{Ln}(m)$, então, o i-ésimo atributo não transmite informações e pode ser removida da análise decisória. Em razão do peso $\tilde{\lambda}_{\mathrm{i}}$ ser inversamente relacionado a $e\left(d_{i}\right)$, usa-se 1-e $\left(d_{i}\right)$ ao invés de $e\left(d_{i}\right)$ e normaliza-se para assegurar que $0 \leq \tilde{\lambda}_{\mathrm{i}} \leq 1$ e $\sum_{\mathrm{i}=1}^{\mathrm{n}} \tilde{\lambda}_{\mathrm{i}}=1$. Sendo assim, a entropia da informação pode vir a ser representada pela seguinte expressão: $\tilde{\lambda}_{\mathrm{i}}=\frac{1}{\mathrm{n}-\mathrm{E}}\left[1-\mathrm{e}\left(\mathrm{d}_{\mathrm{i}}\right)\right]=\frac{\left[1-\mathrm{e}\left(\mathrm{d}_{\mathrm{i}}\right)\right]}{\mathrm{n}-\mathrm{E}}$.

Deste modo, seguindo-se a proposta de Rocha (2010), as seguintes etapas serão seguidas no cálculo da entropia informacional:

(i) cálculo dos indicadores/quocientes da entidade com base em seus dados financeiros;

(ii) criar a matriz de decisão, ou seja, matriz composta pelos indicadores/quocientes selecionados anteriormente;

(iii) criar a matriz resultante da divisão de cada indicador/quociente pelo indicador máximo ou mínimo, conforme propõe a literatura da entropia;

(iv) criar a matriz normalizada por meio da divisão de cada valor da coluna pela soma da própria coluna;

( $v)$ calculam-se as entropias parciais $e\left(d_{i}\right)$; e 
( vi) calculam-se os pesos dos atributos $\left(\lambda_{i}\right)$ - também chamados de peso da informação.

Em suma - quanto maior a entropia menor o peso da informação relativa ao indicador/quociente em observação; ao contrário - quanto menor a entropia maior o peso da informação referente ao indicador/quociente em análise.

\section{Contabilidade e análise de resultado no setor público}

A Contabilidade Governamental brasileira nas últimas décadas tem vivenciado uma série de mudanças em relação à sua legislação. Houve uma sequência de leis, resoluções, decretos, portarias, instruções normativas, etc., que foram estabelecidas, sobretudo, com o objetivo de melhorar o desempenho das finanças públicas. Neste arcabouço de políticas contábeis, duas normas relevam destacar, pois causaram e irão ocasionar bastantes impactos à Contabilidade Pública. Dentre as quais, a Lei Complementar $n^{\circ} 101$ de 2000 ou Lei de Responsabilidade Fiscal (LRF) e a Portaria do Ministério da Fazenda n 184 de 2008.

A primeira tem buscado estabelecer as normas de finanças públicas voltadas para a responsabilidade na gestão fiscal e dá outras providências. Enquanto que a segunda estabeleceu as diretrizes, as quais devem ser observadas no setor público quanto a: procedimentos, práticas, laboração e divulgação das demonstrações contábeis, de forma a torná-los convergentes com as Normas Internacionais de Contabilidade Aplicadas ao Setor Público - tradução da sigla em inglês, International Public Sector Accounting Standards (IPSAS).

O estabelecimento da LRF foi um "marco importante no gerenciamento dos recursos públicos, visando métodos que proporcionem maior eficiência da gestão pública e sustentabilidade da capacidade de investimento desse setor" (SANTOS, 2007, p. 22). Mais precisamente, "A Lei de Responsabilidade Fiscal surge como um instrumento para conter os déficits públicos e $O$ endividamento crescente nas três esferas governamentais" (BARBOSA, 2008, p. 2). Nesse mesmo entendimento, Machado Júnior e Reis (2008) asseveram que a LRF determina que os entes públicos das três esferas realizem os serviços públicos necessários para o bem-estar da sociedade, preservando, basicamente, o princípio do equilíbrio entre receitas e despesas.

No que se refere aos gastos públicos, a LRF preconizou limites às despesas com pessoal e com endividamento público, como, também, aspectos relevantes ao combate de desvios de recursos públicos. Neste contexto, se o ente obtiver arrecadação abaixo do previsto, o mesmo fica impossibilitado de efetuar empenhos, com exceção das despesas de fins obrigatórios; como também se as mesmas forem ressalvadas na Lei de Diretrizes Orçamentárias (LDO) ou se o empenho estiver relacionado ao serviço da dívida. Ressalta-se, também, que a lei coíbe a contratação de empréstimos para cobertura de despesas correntes - tal veto foi por meio da chamada Regra de Ouro (BARBOSA, 2008).

Referente à adoção das normas internacionais de contabilidade pelas entidades governamentais locais, Darós e Pereira (2009, p. 1) preponderam que 
uma das principais mudanças é referente ao "enfoque contábil, eminentemente centrado no controle orçamentário, para uma contabilidade pública patrimonial, com a adoção do regime de competência para as receitas e despesas públicas".

Atualmente, já são 31 IPSAS, emitidas pelo International Accounting Standards Board (IASB). Heald (2003 apud CHAN, 2009) menciona que as IPSAS consistem na peça central para a revolução global da contabilidade governamental, em que é dada maior responsabilização e transparência às finanças públicas. Portanto, as IPSAS tornam-se um fato internacional de referência para avaliar as práticas contábeis dos governos mundiais (HEALD, 2003 apud CHAN, 2009). Assim, as IPSAS trarão um novo conceito de Contabilidade Pública para as entidades governamentais, em que a essência das transações do setor público brasileiro prevalecerá sobre seus aspectos formais, mostrando, deste modo, a situação real das contas públicas nacionais.

A contabilidade governamental, como ramo da ciência contábil, aplica no processo gerador de informações todos os princípios e normas de contabilidade relacionadas ao controle do patrimônio das entidades do setor público; tem, portanto, como objetivo principal fornecer aos seus diversos usuários informações relativas aos resultados alcançados e os aspectos de "natureza orçamentária, econômica, financeira e física do patrimônio da entidade do setor público, em apoio ao processo de tomada de decisão, à adequada prestação de contas e ao necessário suporte para a instrumentalização do controle social" (CONSELHO FEDERAL DE CONTABILIDADE - CFC, 2012, p. 6).

Congruente a isto, a análise dos dados produzidos pela contabilidade pública pode melhorar ainda mais esse processo gerador de informações, pois, como ressalta Lima Júnior (2007, p. 16), a partir de uma cadeia de indicadores econômico-financeiros, "pode-se traduzir os dados apresentados nas demonstrações contábeis de forma simples e prática. Fazendo com que o gestor e demais servidores públicos utilizem esta informação para a tomada de decisão, e não apenas por exigência legal".

Diversos são os indicadores aplicados aos demonstrativos do setor público, sendo os mais comuns, na literatura nacional, os apresentados nas obras de Kohama (1999) e Matias e Campello (2000). Nesta perspectiva, alguns estudos nacionais já foram desenvolvidos, a fim de avaliar os resultados contábeis das entidades públicas locais.

Fernandes (1996) discorreu a respeito da análise de balanços no setor público, destacando, sobretudo, sua importância para o setor. 0 autor elencou os principais métodos tradicionais de análise de balanço, buscando associar estas técnicas ao caso das entidades governamentais. O autor considera que a análise de balanços aplicada ao setor público pode ter a mesma relevância que no setor privado, como também pode superar a este.

Lima Júnior (2007) desenvolveu uma dissertação, objetivando verificar os reflexos da LRF na situação econômico-financeira dos municípios do estado de Santa Catarina, utilizando-se do método de 
Análise das Componentes Principais (ACP). Os resultados da pesquisa mostraram que de trinta e nove indicadores aplicados nas demonstrações contábeis dos municípios, (i) o quociente da estrutura de receita participação do ICMS; (ii) o quociente da estrutura de receita participação da receita tributária; (iii) o quociente da participação do passivo financeiro a descoberto nas receitas orçamentárias; e o (iv) quociente do resultado orçamentário, podem demonstrar a situação econômico-financeira dos municípios de modo geral, como, também, a LRF está relacionada positivamente com 0 equilíbrio financeiro dos entidades observadas.

Coelho e Quintana (2008) desenvolveram uma análise da situação financeira econômica do município de Rio Grande (RS), no período de 2002 a 2005. Os autores enxergaram que no período, de modo geral, o município apresentou uma situação econômica e financeira positiva; contudo, os autores advertiram que a aquisição de bens, créditos e valores permanentes devem ser melhores controlados - para não ocasionar o descontrole da dívida fundada - a fim de evitar déficits patrimoniais futuros.

Nogueira e Rodrigues Júnior (2008) analisaram e interpretaram os demonstrativos contábeis e de gestão fiscal do Estado do Ceará, no período de 2003 a 2007. Os autores verificaram que o Estado, nesse período, conseguiu de forma satisfatória o equilíbrio de suas contas e, especificamente, nos orçamentos correntes e de capital, estando este aproveitamento mais presente entre os anos de 2005 a 2007. Diante destes achados, os autores inferem que algumas das condutas do governo cearense podem ser identificadas por meio das demonstrações contábeis dentre outras informações publicadas - provando que esses demonstrativos podem ser usados para avaliar o comportamento do executivo - i.e., permitindo analisar o desempenho da gestão estadual.

Trevisan et al. (2009) conduziram um estudo na tentativa de estruturar um modelo de indicadores contábeis para avaliar a gestão financeira de municípios, estudando-se especificamente uma prefeitura gaúcha no período de dois anos. Os principais resultados mostraram que a entidade possuía uma boa programação no aspecto orçamentário, i.e., devido ao fato de nos dois anos observados, ter conseguido auferir equilíbrio entre suas receitas estimadas e despesas fixadas. Quanto ao aspecto financeiro, os autores verificaram excesso de vinculação de recursos de curto prazo, "denotando certo engessamento na gestão dos recursos financeiros, índices elevados de liquidez e prazos satisfatórios para o pagamento de fornecedores". Referente à análise patrimonial, os autores constaram uma elevação nos recursos disponíveis, como, também, não identificaram variações no endividamento da entidade.

Bonifácio et al. (2009) desenvolveram uma pesquisa, a fim de identificar a contribuição da análise das demonstrações contábeis para a tomada de decisão no setor público. Ao observar somente o caso de uma prefeitura do Estado de Santa Catarina, nos exercícios de 2005 a 2007; os autores perceberam que análise econômico-financeira pode contribuir na 
tomada de decisões do gestor - pois haverá, por parte do gestor, uma melhor avaliação da aplicação dos recursos públicos - como também permite verificar as falhas eventualmente cometidas, corrigindo-as no exercício seguinte, otimizando-se, deste modo, os resultados pretendidos - atendendo às premissas de economicidade, eficácia no atendimento dos objetivos estabelecidos, além de um melhoramento da eficiência na aplicação dos recursos.

Soares et al. (2011) desenvolveram um estudo objetivando demonstrar em que medida os índices de análise econômico-financeira podem ser empregados na administração pública, a fim de se estabelecer um ranking na gestão dos municípios catarinenses. Apanhando oito indicadores (variáveis), os autores conseguiram verificar, por meio da análise das componentes principais, os melhores municípios em termos de gestão eficiente, tendo como primeiras componentes principais (i) 0 comprometimento com dívidas e (ii) o grau de dependência; a terceira componente principal foi obtida pelas (iii) despesas com pessoal; e a quarta componente principal pelas (iv) despesas com educação.

\section{Método}

\subsection{Delineamento, população e coleta dos dados}

No que se refere ao delineamento da pesquisa - quanto aos objetivos é descritiva, quanto aos meios é documental e, quanto à abordagem do problema quantitativa; em que é investigado o caso dos 26 estados brasileiros mais o Distrito Federal (DF). A coleta dos dados é realizada por meio dos demonstrativos financeiros dos 26 estados brasileiros, mais o DF, disponibilizados por meio do Sistema de Coleta de Dados Contábeis de Estados e Municípios (SISTN), da STN ${ }^{1}$.

\subsection{Técnicas de análise dos dados e variáveis}

No que diz respeito à análise e interpretação dos dados, é feito o uso da técnica da entropia (e), que já foi apresentada na Seção 2. A análise descritiva também é empregada, em que, juntamente com a entropia, é interpretado os dados relativos a uma série estatística histórica de 11 anos (2001 a 2011). Todas as análises e interpretações dos dados serão realizadas considerando-se os indicadores/quocientes (variáveis) financeiros aplicados aos Balanços Orçamentários e Patrimoniais de todas as entidades componentes da amostra no período de 2001 a 2011, subdividos em três séries basicamente: (i) triênio 2001 a 2003; (ii) quadriênio 2004 a 2007; e (iii) quadriênio 2008 a 2011.

No Quadro 3, são apresentados os indicadores/quocientes (variáveis) analisados.

\footnotetext{
${ }^{1}$ Disponível em: <http://www.tesouro.fazenda.gov.br/estados municipios/sistn.asp $>$. Acesso em: set. 2012.
} 
Quadro 3 - Indicadores contábeis levantados no estudo

\begin{tabular}{c|c|c|c|c}
\hline Indicador/Quociente & Sigla & Fórmula & Natureza & Fonte \\
\hline \hline $\begin{array}{c}\text { Indicador Resultado } \\
\text { Orçamentário Total }\end{array}$ & ROT & $\begin{array}{c}\text { Receita Total/Despesa } \\
\text { Total }\end{array}$ & Orçamentária & $\begin{array}{c}\text { Kohama } \\
(1999)\end{array}$ \\
\hline $\begin{array}{c}\text { Indicador do Resultado } \\
\text { Orçamentário Corrente }\end{array}$ & ROC & $\begin{array}{c}\text { Receitas } \\
\text { Correntes/Despesas } \\
\text { Correntes }\end{array}$ & Orçamentária & $\begin{array}{c}\text { Kohama } \\
(1999)\end{array}$ \\
\hline $\begin{array}{c}\text { Indicador do Resultado } \\
\text { Orçamentário de Capital }\end{array}$ & ROP & $\begin{array}{c}\text { Receitas de } \\
\text { Capital/Despesas de } \\
\text { Capital }\end{array}$ & Orçamentária & $\begin{array}{c}\text { Kohama } \\
(1999)\end{array}$ \\
\hline $\begin{array}{c}\text { Indicador da Situação } \\
\text { Financeira }\end{array}$ & SF & $\begin{array}{c}\text { Ativo Financeiro/Passivo } \\
\text { Financeiro }\end{array}$ & Patrimonial & $\begin{array}{c}\text { Kohama } \\
(1999)\end{array}$ \\
\hline $\begin{array}{c}\text { Indicador da Situação } \\
\text { Permanente }\end{array}$ & SP & $\begin{array}{c}\text { Ativo Permanente/Passivo } \\
\text { Permanente }\end{array}$ & Patrimonial & $\begin{array}{c}\text { Kohama } \\
(1999)\end{array}$ \\
\hline $\begin{array}{c}\text { Indicador Resultado } \\
\text { Patrimonial }\end{array}$ & RP & $\begin{array}{c}\text { Ativo Real/Passivo Real } \\
\text { Kohama } \\
(1999)\end{array}$ \\
\hline $\begin{array}{c}\text { Utilização de Capital de } \\
\text { Terceiros }\end{array}$ & UCT & $\begin{array}{c}\text { Passivo Financeiro + } \\
\text { Passivo Permanente) } \\
\text { /Ativo Total }\end{array}$ & Patrimonial & $\begin{array}{c}\text { Matias e } \\
\text { Campello } \\
(2000)\end{array}$ \\
\hline $\begin{array}{c}\text { Participação do Passivonial } \\
\text { Financeiro a Descoberto nas } \\
\text { Receitas Orçamentárias }\end{array}$ & PPFDO & $\begin{array}{c}\text { (Passivo Financeiro - Ativo } \\
\text { Financeiro) /Receita } \\
\text { Corrente }\end{array}$ & Patrimonial & $\begin{array}{c}\text { Matias e } \\
\text { Campello } \\
(2000)\end{array}$ \\
\hline
\end{tabular}

Fonte: Dados da pesquisa.

\subsection{Limitações}

Três limitações básicas podem se apontadas no estudo. A primeira diz respeito ao período escolhido, 2001 a 2011, portanto, possíveis generalizações, fora desta série, não são aceitas. A segunda refere-se à amostra intencional escolhida, os estados brasileiros mais o DF, assim, generalizações estendidas a municípios, por exemplo, não são possíveis. Por fim, a metodologia aplicada, técnica da entropia, que aparece como uma sugestão de ferramenta ao apoio na tomada de decisão pelos gestores públicos. Neste contexto, os resultados apresentados restringemse a sua metodologia, e não são passíveis de generalizações ante outras técnicas matemáticas ou estatísticas.

\section{Resultados}

A fim de desenvolver uma avaliação da assertividade da técnica entrópica, como ferramenta para seleção de indicadores financeiros no setor público, assim com já mencionado na seção 4.2, os dados são apresentados em três séries: (i) triênio de 2001 a 2003; (ii) quadriênio de 2004 a 2007; e (iii) quadriênio de 2008 a 2011.

Os resultados referentes ao triênio de 2001 a 2003 são demonstrados na Tabela 1. Percebe-se que, no período, os indicadores com maior peso de informação são os que apresentam detalhes da situação patrimonial dos estados observados. Por exemplo, em 2001, o indicador com menor entropia (94,9\%), e consequentemente, com maior peso de informação $(29,3 \%)$, foi o quociente que demonstra a situação permanente (SP) dos estados; i.e., o quanto de bens e direitos foi comprometido aos passivos de natureza permanente. Neste contexto, pelo valor médio apresentado (0.575), infere-se que, no ano (2001), os 
estados tiveram um déficit em suas contas de natureza permanente, visto que o indicador ficou abaixo de ' 1 '. Este mesmo cenário ocorreu no ano seguinte, 2002.

No ano de 2003, apesar da maioria dos indicadores com maior peso de informação ser especificamente os de natureza permanente, o indicador com menor entropia $(94,2 \%)$ com maior peso de informação $(29,0 \%)$ foi indicador de natureza orçamentária (ROP), que analisa a execução do orçamento de capital, i.e., o quanto de receitas de capital foram comprometidas na execução dos gastos de capital (gastos que geram bens permanentes, e.g. ativos móveis e imóveis de modo geral). Como se pode observar, por meio da média estatística do indicador, houve um déficit de capital, pois este está abaixo de ' 1 ', inferindo que os recursos de capital não foram suficientes para custear todas as despesas de capital no ano em destaque (2003).

Em todos estes indicadores mencionados, também se percebe a grande dispersão que existe em seus valores médios (ver linha DesvioPadrão), corroborando a literatura da entropia - que dados mais dispersos são aqueles que carregam maior peso de informação; em outras palavras, são dados que melhor precisam ser entendidos e analisados por ser dados que apresentam resultados surpreendentes (ver BENTES; MENEZES; MENDES, 2009). Releva destacar que, no triênio, o indicador com maior entropia e com menor peso de informação foi o indicador que mede a execução do orçamento total (ROT).

Tabela 1 - Grau de entropia e pesos de informação dos indicadores financeiros para o triênio 2004 a 2007

\begin{tabular}{|c|c|c|c|c|c|c|c|c|c|}
\hline \multicolumn{4}{|c|}{ (-) Maior Informação } & \multicolumn{6}{|c|}{ (+) Menor Informação } \\
\hline Ano & Estatísticas & $\mathrm{ROT}^{*}$ & $\mathrm{ROC}^{*}$ & $\mathrm{ROP}^{*}$ & $\mathrm{SF}^{\star *}$ & $\mathrm{SP}^{* *}$ & $\mathrm{RP}^{* \star}$ & $\mathrm{UCT}^{* *}$ & PPFDRO ${ }^{* * *}$ \\
\hline \multirow{4}{*}{2001} & Média & 0.991 & 1.144 & 0.278 & 1.241 & 0.575 & 1.074 & 0.947 & 0.049 \\
\hline & Desvio-Padrão & 0.041 & 0.074 & 0.114 & 1.059 & 0.336 & 0.451 & 0.553 & 0.124 \\
\hline & Entropia (e) & 1.000 & 0.999 & 0.958 & 0.965 & 0.949 & 0.985 & 0.972 & 0.999 \\
\hline & Peso dos atributos $(\lambda)$ & 0.001 & 0.005 & 0.240 & 0.201 & 0.293 & 0.088 & 0.163 & 0.008 \\
\hline \multirow{4}{*}{2002} & Média & 0.988 & 1.206 & 0.377 & 1.260 & 0.571 & 1.080 & 1.007 & 0.043 \\
\hline & Desvio-Padrão & 0.042 & 0.111 & 0.177 & 0.904 & 0.370 & 0.481 & 0.523 & 0.102 \\
\hline & Entropia (e) & 1.000 & 0.998 & 0.948 & 0.959 & 0.943 & 0.986 & 0.982 & 0.999 \\
\hline & Peso dos atributos $(\lambda)$ & 0.002 & 0.010 & 0.281 & 0.221 & 0.307 & 0.075 & 0.098 & 0.007 \\
\hline \multirow{4}{*}{2003} & Média & 0.979 & 1.179 & 0.252 & 2.573 & 0.603 & 1.165 & 0.841 & 0.039 \\
\hline & Desvio-Padrão & 0.036 & 0.094 & 0.126 & 2.836 & 0.342 & 0.461 & 0.413 & 0.071 \\
\hline & Entropia (e) & 1.000 & 0.999 & 0.942 & 0.945 & 0.953 & 0.989 & 0.975 & 0.999 \\
\hline & Peso dos atributos $(\lambda)$ & 0.002 & 0.007 & 0.290 & 0.276 & 0.237 & 0.057 & 0.127 & 0.004 \\
\hline
\end{tabular}

Fonte: Dados da pesquisa.

*Natureza Orçamentária; ${ }^{* *}$ Natureza Patrimonial; ${ }^{* * *}$ Natureza Patrimonial e Orçamentária.

Nota: A metodologia utilizada para o cálculo da entropia (e) e pesos dos atributos $(\lambda)$ está apresentada na seção 2.2 .

Legenda: ROT (Resultado Orçamentário Total); ROC (Resultado Orçamentário Corrente); ROP (Resultado Orçamentário de Capital); SF (Situação Financeira); SP (Situação Permanente); RP (Resultado Patrimonial); UCT (Utilização de Capital de Terceiros); PPFDRO (Participação do Passivo Financeiro a Descoberto nas Receitas Orçamentárias); LRF (Lei de Responsabilidade Fiscal).

Os resultados referentes ao quadriênio 2004 a 2007 são demonstrados na Tabela 2. No ano de 2004, mais uma vez, o indicador que analisa a situação permanente dos estados (SP) foi o que apresentou a menor entropia $(94,7 \%)$ e maior peso de informação $(31,0 \%)$, 
atribuindo-se novamente grande relevância aos indicadores desta natureza.

De modo consecutivo, os anos de 2005, 2006 e 2007 tiveram como indicador de menor entropia e maior peso de informação o indicador que verifica o resultado da execução do orçamento de capital dos estados (ROP). Em todos os anos percebe-se que houve déficits orçamentários de capital, sinalizando mais uma vez que as receitas de capital não foram suficientes para custear todos os gastos de investimentos. Apesar sua natureza orçamentária, é importante mencionar que a execução deste tipo de orçamento, capital, gera novos ativos para entidade pública, por exemplo, bens móveis (material permanente, veículos, móveis e utensílios, etc.) e imóveis (e.g., edifícios, estradas, pontes, escolas, creches, hospitais, etc.). Destaca-se, ainda, que igualmente como ocorrera no triênio anterior, o indicador com maior entropia e menor peso de informação foi o indicador que mostra o resultado de execução dos orçamentos das receitas e despesas totais (ROT). Corroborando a força que a LRF exerce sobre a execução deste orçamento, isto é mais perceptível ao se olhar o valor médio deste indicador, em todos os anos ele foi basicamente igual a ' 1 ', indicando o equilíbrio que deve haver entre as receitas e as despesas dos governos.

Tabela 2 - Grau de entropia e pesos dos indicadores financeiros para o quadriênio 2004 a 2007

\begin{tabular}{|c|c|c|c|c|c|c|c|c|c|}
\hline \multicolumn{4}{|c|}{ (-) Maior Informação } & \multicolumn{6}{|c|}{ (+) Menor Informação } \\
\hline Ano & Estatísticas & $R O T^{*}$ & $R O C^{*}$ & $R O P^{*}$ & $S F^{\star *}$ & $S P^{* *}$ & $R P^{\star *}$ & $U C T^{\star *}$ & $P P F D R O^{* * *}$ \\
\hline \multirow{4}{*}{2004} & Média & 1.005 & 1.229 & 0.237 & 1.285 & 0.589 & 1.231 & 0.850 & 0.021 \\
\hline & Desvio-Padrão & 0.030 & 0.096 & 0.115 & 0.813 & 0.357 & 0.534 & 0.477 & 0.069 \\
\hline & Entropia (e) & 1.000 & 0.999 & 0.949 & 0.978 & 0.947 & 0.988 & 0.970 & 0.999 \\
\hline & Peso dos atributos $(\lambda)$ & 0.001 & 0.008 & 0.298 & 0.130 & 0.310 & 0.072 & 0.176 & 0.004 \\
\hline \multirow{4}{*}{2005} & Média & 1.029 & 1.279 & 0.195 & 2.456 & 0.583 & 1.290 & 0.873 & -0.014 \\
\hline & Desvio-Padrão & 0.040 & 0.103 & 0.106 & 2.185 & 0.374 & 0.644 & 0.531 & 0.096 \\
\hline & Entropia (e) & 1.000 & 0.999 & 0.926 & 0.964 & 0.940 & 0.988 & 0.973 & 0.999 \\
\hline & Peso dos atributos $(\lambda)$ & 0.001 & 0.007 & 0.349 & 0.171 & 0.285 & 0.056 & 0.128 & 0.004 \\
\hline \multirow{4}{*}{2006} & Média & 1.002 & 1.239 & 0.222 & 2.251 & 0.660 & 1.417 & 0.719 & -0.025 \\
\hline & Desvio-Padrão & 0.031 & 0.078 & 0.091 & 1.555 & 0.422 & 0.772 & 0.201 & 0.079 \\
\hline & Entropia (e) & 1.000 & 0.999 & 0.943 & 0.967 & 0.949 & 0.983 & 0.972 & 0.999 \\
\hline & Peso dos atributos $(\lambda)$ & 0.001 & 0.005 & 0.301 & 0.178 & 0.269 & 0.091 & 0.150 & 0.004 \\
\hline \multirow{4}{*}{2007} & Média & 1.035 & 1.238 & 0.195 & 3.084 & 0.642 & 1.476 & 0.755 & -0.058 \\
\hline & Desvio-Padrão & 0.030 & 0.088 & 0.100 & 2.403 & 0.402 & 0.801 & 0.510 & 0.078 \\
\hline & Entropia (e) & 1.000 & 0.999 & 0.921 & 0.961 & 0.942 & 0.980 & 0.941 & 0.999 \\
\hline & Peso dos atributos $(\lambda)$ & 0.001 & 0.005 & 0.308 & 0.151 & 0.226 & 0.078 & 0.229 & 0.004 \\
\hline
\end{tabular}

Fonte: Dados da pesquisa.

*Natureza Orçamentária; **Natureza Patrimonial; *** Natureza Patrimonial e Orçamentária.

Nota: A metodologia utilizada para o cálculo da entropia (e) e pesos dos atributos $(\lambda)$ está apresentada na seção 2.2 .

Legenda: ROT (Resultado Orçamentário Total); ROC (Resultado Orçamentário Corrente); ROP (Resultado Orçamentário de Capital); SF (Situação Financeira); SP (Situação Permanente); RP (Resultado Patrimonial); UCT (Utilização de Capital de Terceiros); PPFDRO (Participação do Passivo Financeiro a Descoberto nas Receitas Orçamentárias).

Os resultados referentes ao quadriênio 2008 a 2011 são demonstrados na Tabela 2. Em 2008 e 2009, consecutivamente, outra vez, o indicador com menor entropia e maior peso de informação é o que 
demonstra a situação permanente dos estados (SP). Neste bimestre verifica-se que os estados apresentaram déficit em suas situações patrimoniais. No ano seguinte, 2010, o indicador com menor entropia $(92,0 \%)$ e maior peso de informação $(83,0 \%)$ foi o indicador que mede 0 resultado patrimonial dos estados (RP), com base na razão entre o ativo real e o passivo real dos estados. Oportunamente, verifica-se que os estados, no ano, tiveram uma situação negativa neste indicador, sinalizando que na soma do ativo financeiro e não financeiro, existe um déficit em relação ao passivo financeiro e não financeiro dos estados; neste contexto, pode-se inferir que, no ano (2010), a liquidez geral das entidades foi considerada insatisfatória.

No ano 2011, a entropia chama maior atenção para o indicador que retrata o endividamento dos estados (UCT). Por meio de seu valor médio, pode-se enxergar que os estados obtiveram um limite de endividamento abaixo de - ' 1 ' - considerado pela literatura como algo satisfatório para as suas finanças, pois o somatório de todos os seus ativos foi suficiente para cobrir todos os seus passivos, restando-Ihes ainda algum capital. Percebese, ainda, que, neste quadriênio, em quase todos os anos, o indicador com maior entropia e menor peso de informação, como ocorrera nos anos anteriores, foi 0 indicador que mostra o resultado da execução orçamentária total entre receitas e despesas (ROT).

Tabela 3 - Grau de entropia e pesos dos indicadores financeiros para o quadriênio 2008 a 2011

\begin{tabular}{|c|c|c|c|c|c|c|c|c|c|}
\hline \multicolumn{4}{|c|}{ (-) Maior Informação } & \multicolumn{6}{|c|}{ (+) Menor Informação } \\
\hline Ano & Estatísticas & $R O T^{*}$ & $R O C^{*}$ & $R O P^{*}$ & $S F^{* *}$ & $S P^{* *}$ & $R P^{* *}$ & $U C T^{* *}$ & PPFDRO *** \\
\hline \multirow{4}{*}{2008} & Média & 1.043 & 1.270 & 0.221 & 3.265 & 0.607 & 1.487 & 0.770 & -0.094 \\
\hline & Desvio-Padrão & 0.031 & 0.083 & 0.100 & 2.433 & 0.402 & 0.826 & 0.491 & 0.083 \\
\hline & Entropia (e) & 1.000 & 0.999 & 0.942 & 0.957 & 0.941 & 0.979 & 0.950 & 0.999 \\
\hline & Peso dos atributos $(\lambda)$ & 0.001 & 0.005 & 0.247 & 0.182 & 0.253 & 0.089 & 0.216 & 0.006 \\
\hline \multirow{4}{*}{2009} & Média & 0.996 & 1.207 & 0.374 & 3.136 & 0.589 & 1.457 & 0.880 & -0.099 \\
\hline & Desvio-Padrão & 0.028 & 0.087 & 0.155 & 2.332 & 0.399 & 0.812 & 0.633 & 0.089 \\
\hline & Entropia (e) & 1.000 & 0.999 & 0.960 & 0.956 & 0.937 & 0.973 & 0.947 & 0.998 \\
\hline & Peso dos atributos $(\lambda)$ & 0.000 & 0.006 & 0.174 & 0.192 & 0.274 & 0.116 & 0.231 & 0.007 \\
\hline \multirow{4}{*}{2010} & Média & 1.003 & 1.206 & 0.384 & 4.033 & 0.687 & 1.485 & 0.868 & -0.107 \\
\hline & Desvio-Padrão & 0.027 & 0.083 & 0.171 & 3.375 & 0.466 & 0.875 & 0.643 & 0.087 \\
\hline & Entropia (e) & 1.000 & 0.999 & 0.952 & 0.949 & 0.930 & 0.920 & 0.949 & 0.998 \\
\hline & Peso dos atributos $(\lambda)$ & 0.001 & 0.005 & 0.158 & 0.169 & 0.230 & 0.264 & 0.168 & 0.007 \\
\hline \multirow{4}{*}{2011} & Média & 1.064 & 1.263 & 0.300 & 3.221 & 0.684 & 1.353 & 0.985 & -0.111 \\
\hline & Desvio-Padrão & 0.089 & 0.141 & 0.146 & 2.069 & 0.497 & 0.862 & 0.783 & 0.072 \\
\hline & Entropia (e) & 0.994 & 0.997 & 0.944 & 0.898 & 0.891 & 0.905 & 0.830 & 0.998 \\
\hline & Peso dos atributos $(\lambda)$ & 0.010 & 0.006 & 0.103 & 0.187 & 0.201 & 0.175 & 0.314 & 0.004 \\
\hline
\end{tabular}

Fonte: Dados da pesquisa.

*Natureza Orçamentária; ${ }^{* \star}$ Natureza Patrimonial; ${ }^{* \star *}$ Natureza Patrimonial e Orçamentária.

Nota: A metodologia utilizada para o cálculo da entropia (e) e pesos dos atributos $(\lambda)$ está apresentada na seção 2.2 .

Legenda: ROT (Resultado Orçamentário Total); ROC (Resultado Orçamentário Corrente); ROP (Resultado Orçamentário de Capital); SF (Situação Financeira); SP (Situação Permanente); RP (Resultado Patrimonial); UCT (Utilização de Capital de Terceiros); PPFDRO (Participação do Passivo Financeiro a Descoberto nas Receitas Orçamentárias).

De modo geral, verificou-se que os indicadores com maior peso de informação e, consequentemente, com menor entropia, foram, em sua grande maioria, os de natureza patrimonial; Por outro lado, os com menor peso de informação e com maior entropia foram os de natureza 
orçamentária - destaque maior para o indicador de execução orçamentária total (ROT), que avalia a execução de todas as receitas e despesas, como demonstra a Figura 1, na qual é feita uma síntese dos resultados obtidos anteriormente.

Figura 1 - Síntese dos resultados

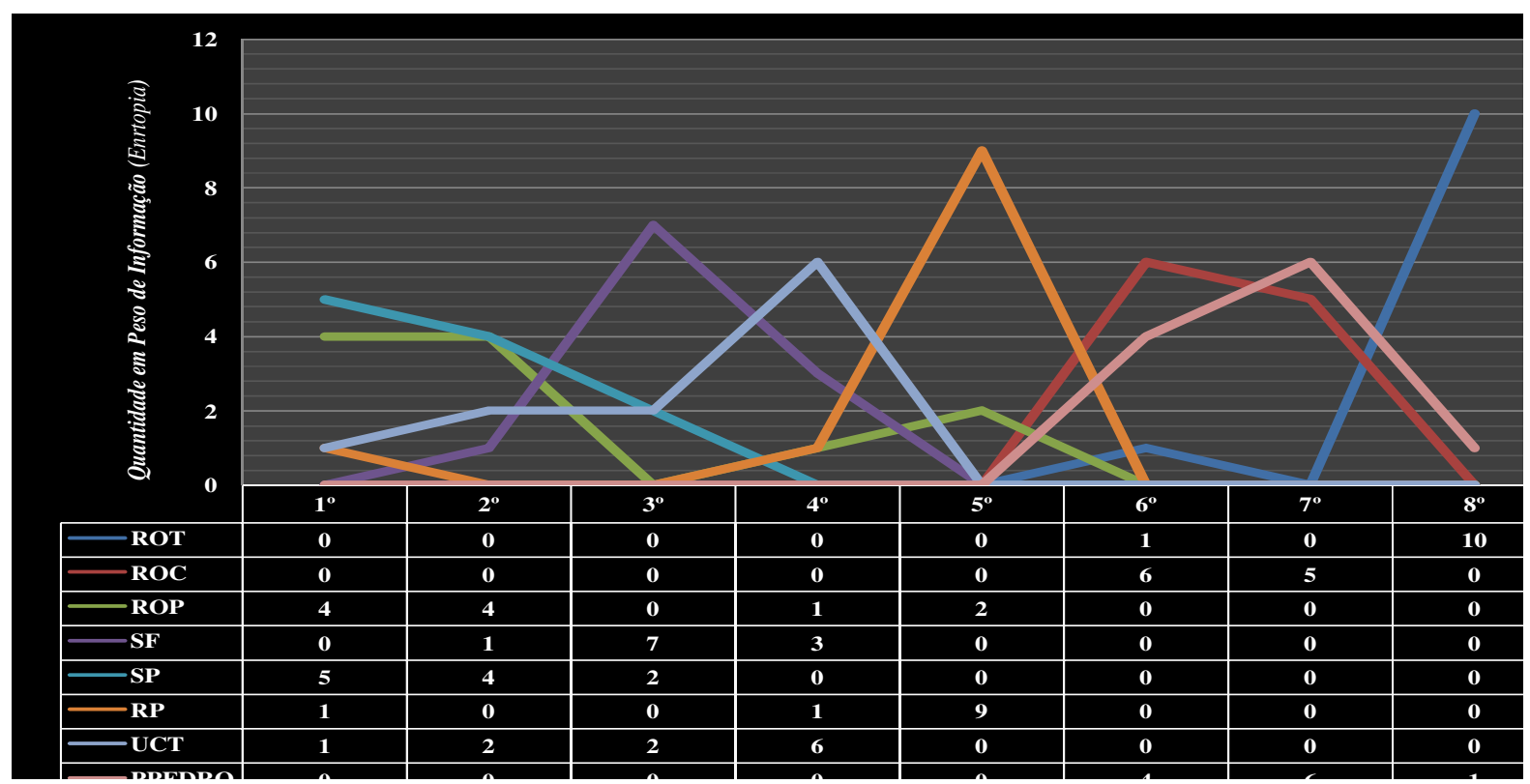

Fonte: Dados da pesquisa.

Legenda: ROT (Resultado Orçamentário Total); ROC (Resultado Orçamentário Corrente); ROP (Resultado Orçamentário de Capital); SF (Situação Financeira); SP (Situação Permanente); RP (Resultado Patrimonial); UCT (Utilização de Capital de Terceiros); PPFDRO (Participação do Passivo Financeiro a Descoberto nas Receitas Orçamentárias).

\section{Estabelecendo-se um raqueamento do - $1^{\circ}$ a $8^{\circ}$ lugar dos} indicadores com maior peso de informação - verifica-se que dos indicadores que estão em primeiro lugar todos eles têm uma relação direta com a informação patrimonial dos estados, por exemplo, SP (cinco vezes) e ROP (quatro vezes). Ao contrário, os indicadores que estão na última posição, em termos de peso informação ( $\lambda i$ ) atribuído pela técnica entrópica, têm-se os de natureza orçamentária, especialmente, o ROT (dez vezes na $8^{\mathrm{a}}$ colação).

\section{Discussão e conclusões}

Ferramentas para apoio à tomada de decisão no setor público ainda são escassas. Embora, seja percebida a evolução no setor público brasileiro, no que diz respeito a sua governança, que caminha paulatinamente a uma gestão de cunho gerencial, deixando, assim, aos poucos, o seu modelo antigo burocrático de governar. Nesta perspectiva, abordagens de novas ferramentas que possam auxiliar os gestores 
públicos a tomarem decisões mais confiáveis são interessantes, quer seja do ponto de vista da academia quer seja na ótica da própria organização pública, que necessita da contribuição daquela para inovar na sua gestão.

Neste contexto, a teoria da informação pode fornecer técnicas interessantes para o processamento de informações mais fidedignas ao usuário, a fim de facilitar a sua tomada de decisão. No campo contábil, uma das funções da Contabilidade é o fornecimento de informações acerca do patrimônio das entidades. A Contabilidade Governamental estende-se ainda mais neste aspecto, pois as informações contábeis no setor público são essenciais para instrumentalização do controle social.

Uma técnica que é defendida por meio da ciência da informação/teoria da informação é a entropia informacional - que pode ser utilizada para selecionar dentro de um conjunto de dados, aqueles mais relevantes, e, quiçá, serem capazes de fazer a diferença em muitas decisões a ser tomadas pelos usuários.

Neste sentido, este artigo teve como propósito verificar, dentre uma seleção não aleatória de indicadores aplicados às demonstrações contábeis do setor público, quais deles possuem o maior peso ou nível de informação medido por meio da entropia informacional e, assim, trazer à baila, o possível uso desta técnica pelas entidades públicas na escolha das informações mais relevantes em suas tomadas de decisões ou aqueles dados que merecem uma análise mais minuciosa por parte do usuário.

Os resultados apontam que, dentre os indicadores intencionalmente selecionados (oito), a técnica da entropia atribuiu maior peso de informação aos indicadores de natureza patrimonial e menor peso aos de natureza orçamentária. Dos indicadores levantados, os com maior peso de informação têm-se: (i) situação permanente (natureza patrimonial); (ii) situação financeira (natureza patrimonial); (iii) resultado orçamentário de capital (natureza orçamentária); (iv) resultado patrimonial (natureza patrimonial); e ( $v$ ) utilização de capital de terceiros. Já os de menor peso de informação, têm-se: (i) resultado orçamentário total (natureza orçamentária); (ii) resultado orçamentário corrente (natureza orçamentária); e (iii) participação do passivo financeiro a descoberto nas receitas orçamentárias.

Estes resultados são contrários, em parte, aos achados de Lima Júnior (2007), que tiveram como indicadores mais relevantes, em seu estudo, os de natureza orçamentária. Também é divergente, em parte, à pesquisa de Nogueira e Rodrigues Júnior (2008), que, também, observou os indicadores de natureza orçamentária como sendo os de maior relevância. Similarmente, estes achados coadunam com os resultados de Coelho e Quintana (2008); Trevisan et al. (2009) e Soares et al. (2011). Nos estudos de Coelho e Quintana (2008) e Trevisan et al. (2009), percebeu-se que, na essência orçamentária, as entidades públicas que foram observadas apresentaram resultados satisfatórios, por conseguirem facilmente o equilíbrio de suas contas de natureza orçamentária, i.e., receita versus despesa. Por outro lado, quando analisados os indicadores de natureza patrimonial, a performance das entidades deixaram a desejar, 
sobretudo, quando apreciado individualmente: as disponibilidades, o endividamento e a imobilização de recursos. Já a pesquisa de Soares et al. (2011) sinalizou, como indicadores mais relevantes no estabelecimento de um ranking de gestão municipal eficiente, dois indicadores de natureza patrimonial.

Nessa perspectiva, este artigo surge como uma contribuição para as literaturas ( $i$ ) da teoria da informação - quando sugere a utilização da entropia informacional como técnica para a análise de resultados do setor público; (ii) da contabilidade e análise de demonstrativos aplicado ao setor público - ao ressaltar que as informações de natureza patrimonial merecem uma melhor atenção, pois nestas informações existem grandes disparidades entre as entidades observadas, conforme foi possível visualizar, por meio da entropia informacional, em que os indicadores com maior peso/nível informacional foram aqueles de natureza patrimonial.

Contudo, os resultados aqui encontrados remetem a um questionamento que pode ser investigado: $(i)$ será que as regras fiscais, apesar de serem de suma importância para o controle das finanças públicas de um país, não têm forçado os gestores públicos a gerenciarem os seus resultados (utilização de métodos criativos) - na tentativa de apresentarem resultados equilibrados - com receio dos danos causados pela regra (e.g., LRF) e, assim, deixarem de receber transferências de governos superiores, adquirirem empréstimos, etc., além de receberem sanções dos seus respectivos tribunais de contas?

Tal constatação, a exemplo, já foi feita por Milesi-Ferretti (2003) que, ao analisar o caso dos estados membros da União Europeia, verificou grande influência do Tratado de Maastricht sobre os orçamentos dessas entidades, neste caso, a perseguição dos gestores por resultados sempre equilibrados. No Brasil, Almeida-Santos, Machado e Scarpin (2012) constatou que, por meio das contas orçamentárias, outras receitas e despesas correntes, os municípios catarinenses conseguem manipular os seus resultados e, assim, auferir o equilíbrio orçamentário.

Contudo, a partir da completa harmonização às Normas Internacionais de Contabilidade do Setor Público (IPSAS), quiçá o Brasil alcançará completamente até ao final de 2015 e, assim, alguns problemas relacionados ao patrimônio público irão paulatinamente ser minimizados. Visto que as IPSAS trarão para o âmbito da Contabilidade Pública brasileira a mudança do enfoque orçamentário para o patrimonial, dessa forma, as entidades locais divulgarão à sociedade, a informação do real valor dos bens públicos.

\section{Referências}

AMORIM, A. D. G. A mediação da informação contábil sob a ótica da ciência da informação. 2007. 110f. Tese (Doutorado em Ciência da Informação) - Universidade de São Paulo, São Paulo, 2007.

ALMEIDA-SANTOS, P. S.; MACHADO, D. G.; SCARPIN, J. E. Gerenciamento de resultados no setor público: análise por meio das 
contas orçamentárias outras receitas e despesas correntes dos municípios de Santa Catarina. Contabilidade Vista \& Revista, v. 23, n. 4, p. 15-43, 2012.

ANDRADE, N. A. Contabilidade pública gestão municipal. São Paulo: Atlas, 2002.

ARAÚJO, C. A. A. A ciência da informação como ciência social. Ciência e Informação, v. 32, n. 3, p. 21-27, 2003.

BARBOSA, R. V. N. Comportamento dos gastos com pessoal entre os anos de 2001 e 2005 nas capitais brasileiras. In: ENCONTRO DA ADMINISTRAÇÃO PÚBLICA E GOVERNANÇA, 2., 2008, Salvador. Anais... Rio de Janeiro: ANPAD, 2008. p. 1-12.

BENTES, S. R.; MENEZES, R.; MENDES, D. A. Entropic measures in nonlinear dynamics. In: SALGUEIRO, M. de F.; MENDES, D. A. ; MARTINS, L. F. (Ed.). Temas em métodos quantitativos: 6. Lisboa: Edições Sílabo, 2009. p. 235-250.

BONIFÁCIO, R. C. et al. As demonstrações contábeis previstas na Lei nº 4.320/64: a análise de resultados como uma forma de contribuição ao gestor público em sua tomada de decisões. In: ENCONTRO DA ANPAD, 33., 2009, São Paulo. Anais... Rio de Janeiro: ANPAD, 2009. p. 1-15.

BORGES, E. P. Irreversibilidade, desordem e incerteza: três visões da generalização do conceito de entropia. Revista Brasileira de Ensino de Física, v. 21, n. 4, p. 453-463, 1999.

BRASIL. Lei $n^{\circ} 4.320$, de 17 de março de 1964. Estatui Normas Gerais de Direito Financeiro para elaboração e contrôle dos orçamentos e balanços da União, dos Estados, dos Municípios e do Distrito Federal. Disponível em: <http://www.planalto.gov.br/ccivil 03/Leis/L4320.htm>. Acesso em: 9 fev. 2012.

BRASIL. Lei Complementar no 101, de 4 de maio de 2000. Estabelece normas de finanças públicas voltadas para a responsabilidade na gestão fiscal e dá outras providências.

Disponível

em:

$<$ http://www.planalto.gov.br/ccivil 03/Leis/LCP/Lcp101.htm>. Acesso em: 9 fev. 2012.

BRASIL. Portaria n‥ 184, de 25 de agosto de 2008. Dispõe sobre as diretrizes a serem observadas no setor público (pelos entes públicos) quanto aos procedimentos, práticas, laboração e divulgação das demonstrações contábeis, de forma a torná-los convergentes com as Normas Internacionais de Contabilidade Aplicadas ao Setor Público. Disponível em: <http://www.fazenda.gov.br/portugues/legislacao/portarias/2008/portaria184.asp>.

Acesso em: 9 fev. 2012.

CHAN, J. L. International Public Sector Accounting Standards: Conceptual and Institutional Issues. In: THE HARMONIZATION OF GOVERNMENT 21 ACCOUNTING AND THE ROLE OF IPSAS, Milan, Itália. p. 1-15.

COELHO, D. M.; QUINTANA, A. C. Análise do desempenho econômico e financeiro de entidades da administração pública direta: o caso da 
prefeitura municipal do Rio Grande (RS). Revista de Contabilidade do Mestrado em Ciências Contábeis da UERJ, v, 13, n. 2, p.1-15, 2008.

COVENEY, P.; HIGHFIELD, R. A flecha do tempo. São Paulo: Siciliano, 1990.

CONSELHO FEDERAL DE CONTABILIDADE (CFC). Normas brasileiras de contabilidade: contabilidade aplicada ao setor público: NBCs T 16.1 a 16.11. Brasília: Conselho Federal de Contabilidade, 2012. Disponível em: $<$ http://portalcfc.org.br/wordpress/wp-

content/uploads/2013/01/Setor P\%C3\%BAblico.pdf>. Acesso em: 18 nov. 2012.

COVOLAN, S. C. T. O conceito de entropia num curso destinado ao ensino médio a partir de concepções prévias dos estudantes e da história da ciência. 2003. 122f. Dissertação (Mestrado em Educação) - Universidade Estadual de Campinas. São Paulo, 2003.

DARÓS, L. L.; PEREIRA, A. S. Análise das normas brasileiras de contabilidade aplicadas ao setor público - NBCASP: mudanças e desafios para a Contabilidade pública. In: CONGRESSO USP DE CONTROLADORIA E CONTABILIDADE, 10., 2009, São Paulo. Anais... São Paulo: USP, 2009. p. 1-12.

EPSTEIN, I. Teoria da Informação. São Paulo: Ática, 1986.

FERNANDES, P. O. Análise de balanços no setor público. Contabilidade Vista \& Revista, v. 7, n. 2, p. 3-10, 1996.

FERNANDES, R. M. S.; AZEVEDO, T. S. Teoria da informação e suas aplicações em compressão e aleatoriedade. 2006. 59f. Monografia (Graduação em Engenharia da Computação) - Instituto Alberto Luiz Coimbra de Pós-Graduação e Pesquisa de Engenharia, Rio de Janeiro, Rio de Janeiro, 2006.

FREIRE, I. M.; NETTO, C. A.; DUARTE, E. N.; RAMALHO, F. A.; DIAS, G. A.; FREIRE, G. H. A. A responsabilidade social da ciência da informação: relato sobre a organização do $X$ Encontro Nacional de Pesquisa em Ciência da Informação. Informação \& Sociedade, v. 20, n. 1, p. 83-91, 2010.

GONÇALVES, L. B. Entropia de Rényi e informação mútua de Cauchy-Schwartz aplicadas ao algoritmo de seleção de variáveis MIFS-U: um estudo comparativo. 2008. 106f. Dissertação (Mestrado em Engenharia Elétrica) - Pontifícia Universidade Católica do Rio de Janeiro, Rio de Janeiro, 2008.

KOHAMA, H. Contabilidade pública: teoria e prática. 10. ed. São Paulo: Atlas, 2009.

LIMA JÚNIOR, R. Análise das demonstrações contábeis dos municípios do estado de Santa Catarina: uma aplicação da técnica estatística análise das componentes principais. 2007. 134f. Dissertação (Mestrado em Ciências Contábeis) - Universidade Regional de Blumenau, Blumenau, 2007.

MACHADO JÚNIOR, J. T.; REIS, H. C. A Lei 4.320 comentada e a Lei de Responsabilidade Fiscal. Rio de Janeiro: Ibam, 2008. 
MATIAS, A. B.; CAMPELLO, C. A. G. B. Administração financeira municipal. São Paulo: Atlas, 2000.

MATTOS R. S.; VEIGA, A. Otimização de entropia: implementação computacional dos princípios Maxent e Minxent. Revista Pesquisa Operacional, v. 22, n. 1, p. 37-59, 2002.

MILESI-FERRETTI, G. M. M. Good, bad or ugly? on the effects of fiscal rules with creative accounting. Journal of Public Economics, v. 88, n. 1/2, p. 377-394, 2003.

NOGUEIRA, A. O.; RODRIGUES JÚNIOR, M. S. Análise e interpretação das demonstrações contábeis no setor público. In: CONGRESSO BRASILEIRO DE CONTABILIDADE, 18., 2008, Gramado. Anais... Brasília: CFC, 2008.

PINEDA, J. O. C. Entropia e teoria da Informação: os fundamentos científicos da era digital. São Paulo: Annablume, 2010.

PINHEIRO, L. V. R.; LOUREIRO, J. M. M. Traçados e limites da ciência da informação. Ciência da Informação, v. 24, n. 1, p. 1-19, 1995.

RIFKIN, J. Entropy: a new world view. New York: The Viking Press, 1980.

ROCHA, I. Grau de entropia da informação em indicadores econômicofinanceiros das empresas que participam dos níveis de governança corporativa da BM\&FBovespa. 2010. 155f. Dissertação (Mestrado em Ciências Contábeis) - Programa de Pós-Graduação em Ciências Contábeis da Universidade Regional de Blumenau, Blumenau, 2010.

SANTOS, S. R. T. O impacto da Lei de Responsabilidade Fiscal nos orçamentos: uma análise do desempenho financeiro dos municípios do Rio Grande do sul de 1997 a 2004. 145f. Dissertação (Mestrado em Ciências Contábeis) - UNISSINOS, São Leopoldo, 2007.

SECRETÁRIA DO TESOURO NACIONAL. Manual de contabilidade aplicado ao setor público. 2011.2 Disponível em: https://www.tesouro.fazenda.gov.br/pt/responsabilidade-fiscal/contabilidadepublica/manuais-de-contabilidade-publica >. Acesso em: 15 nov. 2012.

SHANNON, C. E. The mathematical theory of communication. The Bell System Technical Journal, n. 27, p. 379-423, 1948.

SOARES, M.; LYRA, R. L. W. C.; HEIN, N.; KROENKE, A. O emprego da análise de balanços e métodos estatísticos na área pública: o ranking de gestão dos municípios catarinenses. Revista de Administração Pública, v. 45, n. 5, p. 1425-443, 2011.

SOUZA, R. F.; STUMPF, I. R. C. Ciência da Informação como área do conhecimento: abordagem no contexto da pesquisa e da pós-graduação no Brasil. Perspectivas em Ciência da Informação, v. 14, n. esp., p. 41-58, 2009.

SOUZA, E. E.; DIAS, E. J. W.; NASSIF, M. F. A gestão da informação e do conhecimento na ciência da informação: perspectivas teóricas e práticas organizacionais. Informação \& Sociedade, v. 21, n. 1, p. 55-70, 2011. 
STRASSBURG, U.; FIORI, R.; PARIZOTO, K. G.; BAZZOTTI, C.; FONSECA, E. F. M. A importância do sistema de informação contábil como fonte de informações para tomada de decisões. In: SEMINÁRIO DO CENTRO DE CIÊNCIAS SOCIAIS APLICADAS DE CASCAVEL, 6., 2007, Cascavel. Anais... Cascavel: UNIOESTE, 2007. p. 1-10.

STURZBECHER, M. J. Detecção e caracterização da resposta hemodinâmica pelo desenvolvimento de novos métodos se processamento de imagens funcionais por ressonância magnética. $2006.139 \mathrm{f}$. Dissertação (Programa de Pós-graduação e Física aplicado à Medicina e Biologia) - Universidade de São Paulo, Instituto de Física, São Paulo, 2006.

TREVISAN, R.; LOBER, M. L.; VISENTINI, M. S.; COELHO, M. C.; GRABNER, S. Criação de um modelo de indicadores contábeis para a avaliação da gestão financeira em prefeituras municipais. Pensar Contábil, v. 11, n. 43, p. 24-34, 2009.

ZELENY, M. Multiple criteria decision making. New York: McGraw-Hill, 1982. 